\title{
Transfusion associated CMV infection: Transfusion strategies for high risk patients
}

\author{
Munira Jahan ${ }^{1}$, Shahina Tabassum¹, Abdul Aziz², Munim Ahmed², Md. Nazrul Islam¹ \\ ${ }^{1}$ Department of Virology, BSMMU; 2 Department of Hematology, BSMMU
}

\begin{abstract}
The role of blood and blood products in acquisition of cytomegalovirus (CMV) infections following transfusion was reviewed in this study. CMV IgG prevalence was particularly high in Bangladesh. Thus $\mathbf{9 7 \%}$ of the study groups were found to be CMV IgG positive. The present study showed that CMV IgM antibody prevalence was significantly higher in multiple transfused groups $(24 \%)$ than control group (2\%) indicating CMV primary infection and reactivation or reinfection occur frequently in multitransfused patients. Most CMV infections acquired after transfusion are either asymptomatic or characterized by a self-limited infectious mononucleosis syndrome but it may be serious or fatal in those who are immunocompromised. Particularly at risk are low-birth weight infants, bone marrow and organ transplant patients. If a patient is at high risk of getting CMV diseases, blood from seronegative donors is appropriate and likely to prevent post transfusion CMV infection. Alternatively, blood that has been filtered to decrease the number of white blood cells - the cells that carry CMV - will protect patients from getting a CMV infection from transfusion.
\end{abstract}

Key words : CMV, Transfusion

\section{Introduction}

Considerable circumstantial data strongly suggest that primary infection and reactivation or reinfection with CMV occur frequently after transfusion. Among blood transfusion recipients, a spectrum of responses to cytomegalovirus (CMV) infection has been observed. These include a serological response in the absence of symptoms, the posttransfusion mononucleosis syndrome ${ }^{1}$, polyneuritis ${ }^{2}$, hepatitis ${ }^{3}$, and pericarditis ${ }^{4}$. Whereas, in immunocompromised patients with malignant tumors, especially leukaemias and lymphomas, CMV is of major concern in causing tissue injury and death ${ }^{5}$. This also applies for organ transplant recipients and other immunosuppressed patients ${ }^{6}$. The pathogenesis and the epidemiology of these infections have

Correspondence:

Dr. Munira Jahan

Assistant Professor

Department of Virology

BSMMU

Tel No: 8617099,0171527700

E-mail : mjahan1970@yahoo.com not yet been defined, but blood has been strongly implicated as a vehicle of CMV transmission. However, CMV infection in the transfused patient might also result from reactivation of latent endogenous infection or from exogenous nosocomial sources unrelated to blood products.

The role of allogeneic stimulation in inducing CMV reactivation has been studied in animal models by using organ transplantation, tissue implantation, blood transfusion, or cell transfer. Most of these studies demonstrate that allogeneic stimulation plays an important role in the reactivation of latent $\mathrm{CMV}^{7,8}$. Even in the absence of immunosuppression, there is a higher frequency of reactivation with syngeneic cell transfer or tissue implantation ${ }^{9}$. More recently, reactivation of latent CMV has been achieved by allogeneic stimulation of peripheral blood mononuclear cells in vitro suggesting that allogeneic stimulation may indeed be an important factor in inducing reactivation in vivo ${ }^{10}$. 
It has been known for $>20$ years that CMV may be transmitted by blood ${ }^{1}$. Peripheral blood and bone marrow derived monocyte and granulocyte-macrophage progenitor cells (GM-PS) may be important sites of CMV latency ${ }^{11}$. Presumably, such cell must survive after transfusion and be activated to produce infection in the recipient. The uncertainty concerning how and under what circumstances this occurs may underlie some of the unexplained aspects of transfusion biology. Yeager et al ${ }^{12}$ showed that $\sim 14 \%$ of babies born of seronegative mothers became infected after they were transfused with seropositive blood. The infecting dose of blood was between 50 and $100 \mathrm{ml}$, a remarkably low figure when one considers that one unit of blood $(500 \mathrm{ml})$ Approximately $45 \%$ of patients who yield negative results in tests for antibody to CMV and who undergo cardiopulmonary-bypass perfusion exhibit evidence of CMV infection after the operation ${ }^{13}$. On the basis of the observed incidence of post-transfusion CMV infection, the risk of contracting CMV has been estimated to be $\sim 0.38 \%$ per unit of seropositive blood ${ }^{14}$. They observed that patients who received $>30$ units of cellular blood product had a significant higher risk of acquiring CMV infection. An excellent study by Palohcimo et al. ${ }^{15}$ in 1968 suggested that these infections were primarily associated with transfusion of fresh blood . Another report suggested that only the total volume of blood mattered, not the age of transfused blood ${ }^{16}$. Thus, CMV infection may follow surgery and transfusion with fresh or old blood, though more risk is likely to incur with fresh blood.

\section{Materials \& Methods}

100 Multiple transfused patients consisted of: a) 60 multiple transfused patients with Hereditary haemolytic anaemia and b) 40 patients with chronic renal failure (CRF) getting multiple transfusion and 100 control subjects were tested for IgG and IgM antibody for CMV by ELISA. Multiple transfused patients who were getting at least more than 50 units of blood transfusion and immunocompetent, non transfused controls with no history of fever and rashes within 2 months were included in the study. Samples of control group were collected from the doctors and staffs of BSMMU. 2-3 $\mathrm{ml}$ venous blood was collected to obtain serum for serology and were stored at $-20^{0}$ until the tests were performed. The samples were labeled and case number was recorded on the clinical data sheet immediately. To detect $\operatorname{IgM}$ and $\operatorname{IgG}$ antibodies to CMV in human sera by indirect ELISA, a commercially available kit (Clark laboratories,Inc.Jameston, NY. Cat No.IgG 2325300, IgM 2325250) was used according to the manufacturer's instructions.

\section{Statistical Analysis}

The qualitative and numerical data obtained from the study were entered into SPSS-12.0 for windows and analyzed. Test of significance was estimated by Chi-square test. Probability less than 0.05 were considered as significant.

\section{Results}

Sero-status of IgG in multiple transfused patients $(\mathrm{n}=100)$, and apparently healthy control group $(\mathrm{n}=100)$ was shown in table:1. CMV IgG antibody was detected in all (100\%) of the 100 multiple transfused patients and in $94 \%$ of the 100 apparently healthy persons. IgG response in multiple transfused patients and controls were comparable $(\mathrm{P}>0.05)$.

CMV IgM antibody was detected in $24 \%$ of the 100 multiple transfused patients and $2(2 \%)$ of the 100 apparently healthy persons (Table I). CMV IgM antibody prevalence was significantly higher in multiple transfused groups $((\mathrm{P}<0.01)$ than control groups.

Table I: Serostatus of $\mathrm{IgG}$ and $\operatorname{IgM}$ of $\mathrm{CMV}$ in multitransfused and healthy controls

\begin{tabular}{|c|c|c|c|c|c|c|}
\hline Group of the & \multicolumn{2}{|c|}{ Immunoglobulin $\mathrm{G}$} & \multirow[t]{2}{*}{ Significance } & \multicolumn{2}{|c|}{ Immunoglobulin M } & Significance \\
\hline $\begin{array}{c}\text { study } \\
\text { subjects }\end{array}$ & Positive & Negative & & Positive & Negative & \\
\hline $\begin{array}{l}\text { Multiple } \\
\text { transfused } \\
(\mathrm{n}=100)\end{array}$ & $\begin{array}{c}100 \\
(100.0 \%)\end{array}$ & Nil & & $\begin{array}{c}24 \\
(24.0 \%)\end{array}$ & $\begin{array}{c}76 \\
(76.0 \%)\end{array}$ & \\
\hline $\begin{array}{l}\text { Healthy } \\
\text { control } \\
(\mathrm{n}=100)\end{array}$ & $\begin{array}{c}94 \\
(94.0 \%)\end{array}$ & $\begin{array}{c}6 \\
(6.0 \%)\end{array}$ & $\mathrm{P}>0.05$ & $\begin{array}{c}02 \\
(02.0 \%)\end{array}$ & $\begin{array}{c}98 \\
(98.0 \%)\end{array}$ & $\mathrm{P}<0.01$ \\
\hline Total & 194 (97\%) & $6(3 \%)$ & & $26(13 \%)$ & $174(87 \%)$ & \\
\hline
\end{tabular}

\section{Discussion}

In the current study CMV IgG antibody was detected in $97 \%$ of the study groups including $100 \%$ of multiple transfused patients and even $94 \%$ of the apparently healthy controls were found to be CMV IgG antibody positive. The result reflect the fact that $\mathrm{CMV} \operatorname{IgG}$ prevalence is high in Bangladesh. This high prevalence may be due to lower socioeconomic status, crowded, poor living standard, and child rearing practice in this community. The prevalence of antibody is also significantly higher in developing countries of Africa and Southeast Asia. Mathur et al ${ }^{17}$ reported 83.5\% 
CMV IgG prevalence in Lucknow. The study was carried out 6 months to $>51$ years age range and higher prevalence (91\%) was observed in 31-40 age range. Pal et al ${ }^{18}$ reported 88.75\% CMV IgG prevalence in Northern India. CMV IgG prevalence remained almost constant approaching $100 \%$ in adulthood. A collaborative study of cytomegalovirus antibodies was done by Krech and Tobin ${ }^{19}$ in 19 countries. They reported that the prevalence of antibody varied from $44 \%$ in Oxford to $100 \%$ in Entebbe and Fiji. Stagno et al 20 reported $82 \%$ prevalence of CMV $\operatorname{IgG}$ in Alabama, Birmingham. Whereas $57 \%$ was reported in Washington by Chandler et al ${ }^{21}$ reflecting low prevalence of antibody in Europe, Australia, and parts of North America. This low prevalence is due to higher socioeconomic status.

It is universally recognized that $\operatorname{IgM}$ antibody against a virus is indication of primary infection or reactivation of latent infection. Thus in this study $24 \%$ of 100 multiple transfused patients with CMV IgM antibody either had primary infection or reactivation of latent CMV infection. But $94 \%$ of $\operatorname{IgG}$ prevalence in healthy controls and $100 \%$ in multitransfused patients reflect that the IgM prevalence in this study was may be due to reactivation or reinfection of CMV infection. From the study it appeared that CMV reactivation or reinfection occurred at a higher rate in multi transfused patient due to allogeneic stimulation by transfusion or transfusion transmitted reinfection.

Henle et al 22 estimated that 5 to $12 \%$ of blood donors were carriers of the virus based on serological responses in recipients, and they also found, as confirmed by Prince et $\mathrm{al}^{23}$, a positive correlation between the volume of blood transfused and the risk of CMV seroconversion. CMV infection following transfusion is most likely secondary to reactivation of latent virus either in donor white blood cells or host tissues. Recent studies of neonatal CMV infections acquired following transfusion proved that blood donors with antibodies to CMV (seropositive) are the source of CMV infection for patients lacking antibodies to CMV (seronegative) $^{12}$. Most CMV infections acquired after transfusion are either asymptomatic or characterized by a self-limited infectious mononucleosis syndrome. There are, however, specific groups of patients for whom a primary CMV infection after transfusion may cause significant morbidity and/or mortality. The patients at risk are seronegative and include pregnant women, premature infants, recipients of organ transplants from seronegative donors, and limited groups of severely immunosuppressed oncology patients. Current data suggest that for these seronegative patients the use of blood products from seronegative donors is both appropriate and likely to prevent posttransfusion CMV infection.

Transfusion-associated cytomegalovirus infection (TA-CMV) is associated with considerable morbidity and mortality in atrisk populations, which include CMV-seronegative neonates, patients with AIDS, and stem cell transplant (SCT) recipients. The provision of CMV-seronegative blood product support to these individuals became the standard of care in the late 1980s after studies showed this strategy significantly reduced the rate of TA-CMV $12,24,25$. Donor population, however, vary considerably in their seropositivity rates, a situation thus limiting the available supply of seronegative bloods in some areas like Bangladesh. Thus, alternate methods for the provision of "CMV-safe" blood products have been pursued.

Studies have demonstrated that CMV is latent in cells of the monocyte/macrophage lineage and that these cells can support CMV replication ${ }^{26}$. Third-generation filters effectively remove approximately $3-\log _{10}$ of the contaminating leukocytes in blood products ${ }^{27}$,thus reducing the probability of TA-CMV.

\section{References}

1. Kaariainen L, Klemola E, Paloheimo J. Rise of cytomegalovirus antibodies in an infectiousmononucleosis- like syndrome after transfusion. Br Med J 1966; 1:1270-1272.

2. Constantino $\mathrm{T}$ and Weintraub A. The Guillain-Barre syndrome as a complication of the postperfusion syndrome. Am Heart J 1972; 84:678-680.

3. Toghill PJ, Bailey ME, Williams R, Zeegan R, Bown R. Cytomegalovirus hepatitis in the adult. Lancet 1967; 1:1351-1354.

4. Klemola E, Kiaariainen L, Von Essen R, Haltia K, Koivuniemi A, Von Bonsdorff C. Further studies on cytomegalovirus mononucleosis in previously healthy individuals. Acta Med Scand 1967; 182:311-322.

5. Duvali CP, Casazza AR, Grimley PM, Carbone PP, Rowe WP. Recovery of cytomegalovirus from adults with neoplastic disease. Ann Intern Med 1965; 64 (3): 531541.

6. Craighead JE. Immunologic response to cytomegalovirus infection in renal allograft recipients. Am J Epidemiol 1969; 90:506-513.

7. Cheung KS, and Lang DJ. Transmission and activation 
of cytomegalovirus with blood transfusion: a mouse model. J Infect Dis 1977; 135: 841-845.

8. Gerna G, Zipeto D, Parea M, et al. Monitoring of cytomegalovirus infections and ganciclovir treatment in heart transplant receipents by determination of viremia, antigenemia, and DNAemia. J Infect Dis 1991;164: 488-498.

9. Mayo D, Armstrong JA, Ho M. Activation of latent murine cytomegalovirus infection: co cultivation, cell transfer, and the effect of immunosuppression. J Infect Dis 1978; 138: 890-896.

10. Soderberg-Naucler C, Fish KN, Nelson JA. Reactivation of latent human cytomegalovirus by allogeneic stimulations of blood cells from healthy donors. Cell 1997; 91:119-126.

11. Hahn GR, Jores, Macarski ES. Cytomegalovirus remain latent in a common precursor of dendritic and myeloid cells. Proc Natl Acad Sci USA 1998; 95: 3937-3942.

12. Yeager AS, Grumet FC, Hafleigh EB, Arvin AM, Bradley JS, Prober CG. Prevention of transfusion acquired cytomegalovirus infection in newborn infants. J Pediatrics 1981; 98: 281-287.

13. Embil JA, Folkins DF, Haldane EV, Van Rooyen CE. Cytomegalovirus infection following extracorporeal circulation in children. Lancet 1968; 2: 1151-1155.

14. Preiksaitis JK, Brown L, McKenzie M. The risk of cytomegalovirus infection in seronegative transfusion recipients not receiving exogenous immunosuppression. J Infect Dis 1988;157 (3): 523-529.

15. Paloheimo JA, Von Essen R, Klemola E, Kaariainen L, Siltanen P. Sub clinical cytomegalovirus infections and cytomegalovirus mononucleosis after open heart surgery. Am J Cardiol 1968 ; 22: 624-630.

16. Stevens DP, Barker LF, Ketcham AS, Meyer HM. Asymptomatic cytomegalovirus infection following blood transfusion in tumor surgery. JAMA 1970; 211(8): 1341-1344.

17. Mathur A, Jindal I, Chaturvedi UC. A serological study of cytomegalovirus infection on Lacknow. Ind J Med Res 1981;73: 678-681.

18. Pal SR, Chitkara NL, Krech U. Sero-epidemiology of cytomegalovirus infection in and around Chandigarh (Northern India). Ind J Med Res 1972; 60 (7): 973-978.
19. Krech U, Tobin J. A collaborative study of cytomegalovirus antibodies in mothers and young children in 19 countries. Bulletin Of The World Health Organization 1981; 59 (4): 605-610.

20. Stagno S, Reynolds DW, Huang E-S, Thames S D, Smith R J, Alford CA. Congenital cytomegalovirus infection: Occurrence in an immune population. $\mathrm{N}$ Eng $\mathrm{J}$ Med 1977; 296: 1254-1258.

21. Chandler SH, Alexander ER, Holmes KK. Epidemiology of cytomegaloviral infection in a heterogeneous population of pregnant women. J Infect Dis 1985; 152: 249-256.

22. Henle, WG, Henle M, Scriba C R, et al. Antibody responses to the Epstein-Barr virus and cytomegaloviruses after open-heart and other surgery. $\mathrm{N}$ Engl J Med 1970; 282:1068-1074.

23. Prince AM, Szmuness W, Millian SJ, David DS. A serologic study of cytomegalovirus infections associated with blood transfusions. N Engl J Med 1971; 284:11251131.

24. Bowden RA, Sayers $\mathrm{M}$, Flournoy $\mathrm{N}$, et al. Cytomegalovirus immune globulin and seronegative blood products to prevent primary cytomegalovirus infection after marrow transplantation. N Engl J Med 1986;314:1006-1010

25. Miller WJ, McCullough J, Balfour HH, et al. Prevention of cytomegalovirus infection following bone marrow transplantation: a randomized trial of blood product screening. Bone Marrow Transplant 1991;7:227-234.

26. Stoddart CA, Cardin RD, Boname JM, Manning WC, Abenes GB, Mocarski ES. Peripheral blood mononuclear phagocytes mediate dissemination of murine cytomegalovirus. J Virol 1994;68:6243-6253.

27. Preiksaitis JK. The cytomegalovirus-"safe" blood product: is leukoreduction equivalent to antibody screening? Transfusion Med Rev 2000;14:112-136 